Research Article

\title{
Galloping Stability and Aerodynamic Characteristic of Iced Transmission Line Based on 3-DOF
}

\author{
Xiaohui Liu $\mathbb{D}^{1},{ }^{1}$ Ming Zou $\mathbb{D}^{2},{ }^{2}$ Chuan $W u,{ }^{3}$ Bo Yan $\mathbb{D}^{4},{ }^{4}$ and Mengqi Cai $\mathbb{D}^{5}$ \\ ${ }^{1}$ State Key Laboratory of Mountain Bridge and Tunnel Engineering, Chongqing Jiaotong University, Chongqing 400074, China \\ ${ }^{2}$ College of Civil Engineering, Chongqing Jiaotong University, Chongqing 400074, China \\ ${ }^{3}$ State Grid Henan Electric Power Research Institute, Zhengzhou 450052, China \\ ${ }^{4}$ College of Aerospace Engineering, Chongqing University, Chongqing 400044, China \\ ${ }^{5}$ College of Architecture and Civil Engineering, Chengdu University, Chengdu 610106, China
}

Correspondence should be addressed to Xiaohui Liu; cqdxlxh@126.com

Received 15 May 2020; Revised 3 August 2020; Accepted 28 August 2020; Published 8 September 2020

Academic Editor: Francesco Franco

Copyright $\odot 2020$ Xiaohui Liu et al. This is an open access article distributed under the Creative Commons Attribution License, which permits unrestricted use, distribution, and reproduction in any medium, provided the original work is properly cited.

\begin{abstract}
A new calculation method of critical wind speed based on three degrees of freedom (3-DOF) is proposed for galloping problem of iced transmission line. Based on the quasistatic theory, the aerodynamic load of iced transmission line is obtained, which considers the influence of transverse and torsional motion on the relative wind angle of attack. Finally, the equivalent galloping model of 3DOF iced transmission line is established. At the initial angle of attack, the aerodynamic load is expanded by Taylor, and the unsymmetrical linear aerodynamic coefficient matrix is obtained. The Routh-Hurwitz criterion is used to judge the stability of iced transmission line system, and then the critical wind speed is calculated. The in-plane and out-plane frequencies corresponding to the first-order mode of the transmission line are solved by the analytical method and numerical simulation method. The results obtained by the two methods are compared and verified. The influence of dimensionless transmission line parameter $\lambda$ on the in-plane and out-of-plane frequencies is discussed. The aerodynamic coefficients of the iced transmission line are measured by wind tunnel test and the aerodynamic characteristics are analyzed. According to the theoretical formula, the critical wind speed is calculated by MATLAB. The critical wind speed determined in this paper is compared with the critical wind speed determined by Den Hartog and Nigol theory. The influences of torsional vibration frequency, ice thickness, and ice shape on critical wind speed are analyzed. The research results of this paper have important theoretical significance for the stability judgment of iced transmission lines.
\end{abstract}

\section{Introduction}

Galloping is the self-excited vibration of transmission line under the action of wind load [1]. In winter, the transmission line is easy to be covered with ice, which will not only increase the gravity of the transmission line, but also cause the cross section of the transmission line to become asymmetrical. Icing is not only an important cause of transmission line galloping, but also a difficult problem [2]. Large vibration for a long time will cause serious accidents such as bolt loosening, broken hardware ring, transmission line breaking, tower arm damage, and tower collapse, which will cause huge loss to people's life and property. Therefore, it is of great engineering significance to study the conditions of galloping [3].

In the field of transmission line galloping research, three major galloping theories are widely accepted internationally. The first is the single-degree-of-freedom vertical galloping theory proposed by the American scholar Hartog [4]. This theory considers the main vibration of transmission line but ignores the influence of horizontal vibration and torsional vibration on galloping. Later, based on this theory, Parkinson [5], Davenport [6], and Iwan [7] developed this theory. The second is the torsional galloping theory proposed by Canadian scholar Nigol et al. $[8,9]$. According to this theory, the galloping of transmission line is caused by 
torsional vibration, and lateral vibration is not considered. The third is the eccentric inertial coupled galloping theory proposed by Japanese scholar Yu et al. [10]. This theory considers the eccentric coupling and ignores the influence of lateral vibration on galloping of transmission lines.

Based on the three galloping theories, experts and scholars all over the world have done a lot of research work. Liu et al. studied the characteristics of free vibration of multispan transmission [11]. McClure et al. proposed a macromodeling method for linear dynamic analysis, focusing on capturing the significant characteristics of the propagation of such impact loads in the online section [12]. Liu et al. analyzed the relationship between the galloping amplitude of the conductor and its influencing factors by using the single-degree-of-freedom model; only the singledegree-of-freedom vibration is considered [13]. John established a quasi-steady aerodynamic model for the vibration of an arbitrary cylinder with two translational degrees of freedom; the coupling vibration between the two degrees of freedom is considered [14]. In ABAQUS software, Yan et al. obtained a torsion degree of freedom cable element used to simulate the icing conductor. The two-dimensional flow around a tetrad conductor covered with different thickness of crescent ice is numerically simulated $[15,16]$. The above research is mainly analyzed by numerical simulation method, which can get the results under specific circumstances, and the results are lack of universal applicability. At the same time, some necessary experiments are carried out to verify the results of numerical simulation [15].

In terms of the conductor mode and frequency, Angelo et al. established a nonlinear cable model that can be twisted. The motion is controlled by the classical equation of fully flexible cable and another equation that controls the development of torsion [17, 18]. Gurung et al. proposed a multichannel modal analysis method composed of random decrement method and feature system implementation algorithm to identify galloping [19]. Barbieri et al. tried to establish a method to identify the cable damping of transmission lines, to estimate the system damping matrix with a simple method [20]. Triantafyllou et al. deduced the in-plane modal and natural frequency formulas of the stay cable $[21,22]$. Many scholars have studied the influence of gravity components from other perspectives [23, 24].

To sum up, scholars have studied galloping for a long time and obtained some results. However, because galloping is a kind of complex nonlinear vibration involving coupling between fluid and structure, there are still many problems not completely solved. As far as the authors know, most of the calculation models of the conductor galloping mechanism are based on single degree of freedom and two degrees of freedom, so it is not accurate to judge galloping. In an actual situation, galloping of transmission lines is basically a coupling vibration of 3-DOF, and energy will be transferred in the direction of 3-DOF. The galloping models of single degree of freedom and two degrees of freedom cannot meet the actual engineering requirements. Because of the coupling of galloping in horizontal, vertical, and torsional directions, galloping becomes more complex. It is necessary to establish a more accurate 3-DOF galloping model to deduce the galloping determination formula. The existing research focuses on the use of numerical simulation, and the conclusions are not universally applicable. As far as the author knows, considering the changes in wind field and conductor position at different times, the galloping mechanical model of the iced conductor with three degrees of freedom has not been studied. Based on the quasistatic theory, a 3-DOF vibration mechanical model for galloping of the iced conductor is established in this paper. The influence of the conductor structure parameters on the stability of the iced conductor is studied. The critical wind speed of the iced conductor is calculated by MATLAB software based on the stability discriminant.

\section{Model Building}

2.1. Galloping Mechanical Model. The high-voltage transmission lines that have galloping are mainly in open areas outside the city. In the open area, we assume that the wind speed does not change along the direction of the conductor, so this paper mainly studies the influence of stable wind on galloping. For the open area, we think the shape of ice covering along the line direction is the same. Based on the above assumption, the partial differential equation of continuum vibration can be transformed into the ordinary differential equation of cross section vibration by modal truncation method, which simplifies the complex problems. In this way, a simple and convenient formula can be obtained. The common iced shapes are crescent and sector, and the cross sections of both are symmetrical, so the displacement equation and dynamic equation of the two are the same. In this paper, the crescent ice is selected as an example to establish the mechanical model. For the 3-DOF mechanical model for analyzing galloping stability, as shown in Figure 1, it is assumed that the steady wind flows through the iced conductor from left to right, and the wind speed is $U$. Assuming that after the wind load is applied, the axis of symmetry of the iced conductor at rest is $o Z$, and the angle between the axis of symmetry and the horizontal direction is the initial angle of attack $\alpha_{0}$, which is an important parameter for studying galloping of iced transmission line. The dynamic torsional angle of the conductor is $\theta$, and the symmetry axis of the iced conductor after vibration is $o Z^{\prime}$. The mass of the cross section of the equivalent iced conductor is $m$. The restraint stiffness in horizontal direction, vertical direction, and torsional direction are $K_{z}, K_{y}$, and $K_{\theta}$, respectively.

In this paper, the quasistatic theory [25] is used to calculate the wind load on the iced conductor. The relative relationship between the conductor and the wind field is shown in Figure 2. The lift, drag, and torque of the iced conductor are $F_{L}, F_{D}$, and $M$, respectively. The lift $F_{L}$ is perpendicular to the relative wind speed $U_{r}$, and the $\operatorname{drag} F_{D}$ is parallel to the relative wind speed $U_{r}$. The radius of the conductor is $R$. Under wind load, the speed $\dot{z}$ will be generated when the conductor moves along the horizontal direction, where the superscript point indicates the time derivative, so the relative wind speed of the conductor in the horizontal direction is $U-\dot{z}$. When the conductor vibrates 


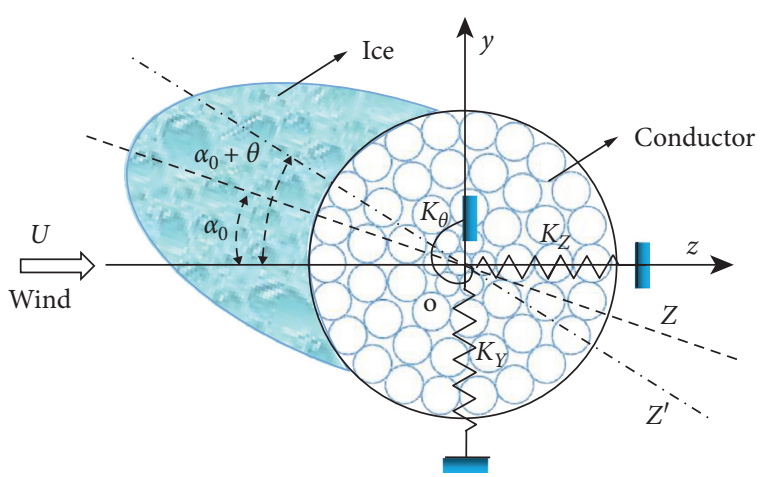

Figure 1: Cross section mechanical model of the iced conductor.

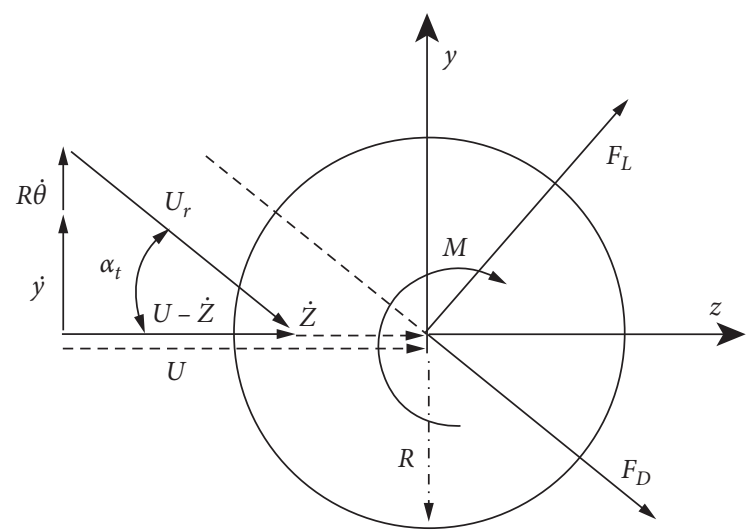

Figure 2: Relative flow.

in torsion, the conductor will twist around the center of the conductor section due to the restraint of both ends of the conductor, so the torsion radius of the conductor is $R$. In actual situation, the torsion angle of the conductor is relatively small. The vertical motion of the conductor will produce velocity $\dot{y}$, and the torsional motion of the conductor will also produce vertical velocity component $R \dot{\theta}$, so the relative velocity of the conductor in the vertical direction is $\dot{y}+R \dot{\theta}$.

Therefore, the actual relative wind speed $U_{r}$ is

$$
U_{r}=\sqrt{(U-\dot{z})^{2}+(R \dot{\theta}+\dot{y})^{2}} .
$$

The relative wind attack angle $\alpha(t)$ can be calculated by the following formula:

$$
\begin{aligned}
\alpha(t) & =\alpha_{0}+\theta(t)-\alpha_{t}(t), \\
\alpha_{t}(t) & =\arctan \left(\frac{R \dot{\theta}+\dot{y}}{U-\dot{z}}\right),
\end{aligned}
$$

where $\theta(t)$ is the dynamic torsional angle of the conductor and $\alpha_{t}(t)$ is the amount of change in angle due to the change in relative wind speed. The lift $F_{L}$, drag $F_{D}$, and torque $M$ of the iced conductor can be obtained by the following formula:

$$
\left[\begin{array}{c}
F_{L}(t) \\
F_{D}(t) \\
M(t)
\end{array}\right]=\frac{1}{2} \rho d U_{r}^{2}\left[\begin{array}{c}
C_{L}(\alpha) \\
C_{D}(\alpha) \\
d C_{M}(\alpha)
\end{array}\right]
$$

where $\rho$ is the air density and $d$ are the conductor diameter. $C_{D}$, $C_{L}$, and $C_{M}$ are the drag coefficient, lift coefficient, and torque coefficient of the iced conductor, respectively. When solving the vibration equation of the iced conductor, it is necessary to project the lift and drag onto the $z$-axis and $y$-axis:

$$
\begin{aligned}
& F_{z}(t)=F_{D} \cos \left(\alpha_{t}\right)+F_{L} \sin \left(\alpha_{t}\right)=\frac{1}{2} \rho d U^{2} C_{z}(\alpha), \\
& F_{y}(t)=F_{L} \cos \left(\alpha_{t}\right)-F_{D} \sin \left(\alpha_{t}\right)=\frac{1}{2} \rho d U^{2} C_{y}(\alpha), \\
& M(t)=\frac{1}{2} \rho d^{2} U^{2} C_{\theta}(\alpha),
\end{aligned}
$$

where $C_{z}, C_{y}$, and $C_{\theta}$ are aerodynamic coefficients in the horizontal, vertical, and torsional directions, respectively, which can be expressed as

$$
\left[\begin{array}{c}
C_{z}(\alpha) \\
C_{y}(\alpha) \\
C_{\theta}(\alpha)
\end{array}\right]=\left(\frac{U_{r i}}{U}\right)^{2}\left[\begin{array}{c}
C_{D} \cos \left(\alpha_{t}\right)+C_{L} \sin \left(\alpha_{t}\right) \\
C_{L} \cos \left(\alpha_{t}\right)-C_{D} \sin \left(\alpha_{t}\right) \\
C_{M}\left(\alpha_{t}\right)
\end{array}\right] .
$$

At the initial wind attack angle $\alpha_{0}$, the horizontal, vertical, and torsional aerodynamic coefficients can be Taylor expanded, the linear part of which can be expressed as

$$
\left[\begin{array}{c}
C_{z}(\alpha) \\
C_{y}(\alpha) \\
C_{\theta}(\alpha)
\end{array}\right]=\left[\begin{array}{c}
C_{z}\left(\alpha_{0}\right) \\
C_{y}\left(\alpha_{0}\right) \\
C_{\theta}\left(\alpha_{0}\right)
\end{array}\right]+\left[\begin{array}{l}
\left.\partial C_{z}\right|_{\alpha=\alpha_{0}} \\
\left.\partial C_{y}\right|_{\alpha=\alpha_{0}} \\
\left.\partial C_{\theta}\right|_{\alpha=\alpha_{0}}
\end{array}\right]\left[\begin{array}{llll}
\frac{\dot{z}_{1}}{\partial \dot{z}_{1}} & \frac{\dot{y}_{1}}{\partial \dot{y}_{1}} & \frac{\dot{\theta}_{1}}{\partial \dot{\theta}_{1}} & \frac{\theta}{\partial \theta}
\end{array}\right],
$$

where $\dot{z}_{1}=(\dot{z} / U), \quad \dot{y}_{1}=(\dot{y} / U), \quad \dot{\theta}_{1}=(R \dot{\theta} / U)$. Combining equations (4) and (6), the linear part of the aerodynamic load can be expressed as follows:

$$
\left\{\begin{array}{c}
F_{y} \\
F_{z} \\
M
\end{array}\right\}=C_{a}\left\{\begin{array}{l}
\dot{y}_{1} \\
\dot{z}_{1} \\
\dot{\theta}_{1}
\end{array}\right\}+K_{a}\left\{\begin{array}{c}
y \\
z \\
\theta
\end{array}\right\}+O\left(\varepsilon^{2}\right),
$$

where $C_{a}$ is the load damping matrix, which can be expressed as

$$
C_{a}=\frac{1}{2} \rho d U^{2}\left[\begin{array}{cc}
\frac{\partial C_{y}}{\partial \alpha_{t}} & \frac{\partial C_{y}}{\partial U_{r}} \\
\frac{\partial C_{z}}{\partial \alpha_{t}} & \frac{\partial C_{z}}{\partial U_{r}} \\
d \frac{\partial C_{\theta}}{\partial \alpha_{t}} & d \frac{\partial C_{\theta}}{\partial U_{r}}
\end{array}\right]\left[\begin{array}{lll}
\frac{\partial \alpha_{t}}{\partial \dot{y}_{1}} & \frac{\partial \alpha_{t}}{\partial \dot{z}_{1}} & \frac{\partial \alpha_{t}}{\partial \dot{\theta}_{1}} \\
\frac{\partial U_{r}}{\partial \dot{y}_{1}} & \frac{\partial U_{r}}{\partial \dot{z}_{1}} & \frac{\partial U_{r}}{\partial \dot{\theta}_{1}}
\end{array}\right] .
$$


$K_{a}$ is the linear relationship between aerodynamic force and motion displacement, which can be expressed as

$$
K_{a}=\frac{1}{2} \rho d U^{2}\left[\begin{array}{ccc}
0 & 0 & \frac{\partial C_{y}}{\partial \alpha} \frac{\partial \alpha}{\partial \theta} \\
0 & 0 & \frac{\partial C_{z}}{\partial \alpha} \frac{\partial \alpha}{\partial \theta} \\
0 & 0 & d \frac{\partial C_{\theta}}{\partial \alpha} \frac{\partial \alpha}{\partial \theta}
\end{array}\right]
$$

At the initial wind angle of attack $\alpha_{0}, \dot{z}_{1}=\dot{y}_{1}=\theta_{1}=0$, combining equations (1), (2), and (5), the elements of load damping matrix and load stiffness matrix are derived and simplified. The simplified load damping matrix is

$$
\left.C_{a}\right|_{\dot{z}_{1}=\dot{y}_{1}=\dot{\theta}_{1}=0}=\frac{1}{2} \rho d U^{2}\left[\begin{array}{ccc}
-\frac{\partial C_{L}}{\partial \alpha}-C_{D} & -2 C_{L} & -\frac{\partial C_{L}}{\partial \alpha}-C_{D} \\
-\frac{\partial C_{D}}{\partial \alpha}+C_{L} & -2 C_{D} & -\frac{\partial C_{D}}{\partial \alpha}+C_{L} \\
-d \frac{\partial C_{M}}{\partial \alpha} & -2 d C_{M} & -d \frac{\partial C_{M}}{\partial \alpha}
\end{array}\right] .
$$

The simplified $K_{a}$ is

$$
\left.K_{a}\right|_{\dot{z}_{1}=\dot{y}_{1}=\dot{\theta}_{1}=0}=\frac{1}{2} \rho d U^{2}\left[\begin{array}{ccc}
0 & 0 & \frac{\partial C_{L}}{\partial \alpha} \\
0 & 0 & \frac{\partial C_{D}}{\partial \alpha} \\
0 & 0 & d \frac{\partial C_{M}}{\partial \alpha}
\end{array}\right] .
$$

$$
C=C_{d}-C_{a}=\left[\begin{array}{c}
\frac{1}{2} \rho d U\left(\frac{\partial C_{L}}{\partial \alpha}+C_{D}\right)+2 m \omega_{y} \zeta_{y} \\
\frac{1}{2} \rho d U\left(\frac{\partial C_{D}}{\partial \alpha}-C_{L}\right) \\
\frac{1}{2} \rho d^{2} U \frac{\partial C_{M}}{\partial \alpha}
\end{array}\right.
$$

2.2. Stability Condition. When only vertical vibration is considered, according to the Den Hartog galloping criterion, the first term of the diagonal element in formula (14) is the criterion for judging galloping. When the following conditions are met, the system is in a stable state:
If only the vibration of the iced conductor under static load is considered and the inertia coupling term and load stiffness term are ignored, the vibration equation of the iced conductor with 3-DOF can be obtained:

$$
M \ddot{X}+C_{d} \dot{X}+K X=C_{a} \dot{X},
$$

where $M$ is the mass matrix, $K$ is the inherent stiffness matrix, $C_{d}$ is the inherent damping matrix, and $X$ is the displacement matrix. Each term means

$$
\begin{aligned}
M & =\left[\begin{array}{lll}
m & 0 & 0 \\
0 & m & 0 \\
0 & 0 & J
\end{array}\right], \\
K & =\left[\begin{array}{ccc}
K_{y} & 0 & 0 \\
0 & K_{z} & 0 \\
0 & 0 & K_{\theta}
\end{array}\right], \\
C_{d} & =\left[\begin{array}{ccc}
2 m \omega_{y} \zeta_{y} & 0 & 0 \\
0 & 2 m \omega_{z} \zeta_{z} & 0 \\
0 & 0 & 2 J \omega_{\theta} \zeta_{\theta}
\end{array}\right], \\
X & =\left\{\begin{array}{c}
y \\
z \\
\theta
\end{array}\right\},
\end{aligned}
$$

where $m$ is the mass per unit length of the iced conductor and $J$ is the moment of inertia. $K_{y}, K_{z}$, and $K_{\theta}$ are the equivalent restraint stiffness of the iced conductor in vertical, horizontal, and torsional direction, respectively. $\zeta_{y}, \zeta_{Z}$, and $\zeta_{\theta}$ are the damping ratios of the iced conductor in vertical, horizontal, and torsional directions, respectively. $\omega_{y}, \omega_{z}$, and $\omega_{\theta}$ are the circular frequencies of the iced conductor in the vertical, horizontal, and torsional directions, respectively. According to formulas (10) and (12), the damping matrix of the system is

$$
\left.\begin{array}{cc}
\rho d U C_{L} & \frac{1}{2} \rho d U\left(\frac{\partial C_{L}}{\partial \alpha}+C_{D}\right) \\
\rho d U C_{D}+2 m \omega_{z} \zeta_{z} & \frac{1}{2} \rho d U\left(\frac{\partial C_{D}}{\partial \alpha}-C_{L}\right) \\
\rho d^{2} U C_{M} & \frac{1}{2} \rho d^{2} U \frac{\partial C_{M}}{\partial \alpha}+2 J \omega_{\theta} \zeta_{\theta}
\end{array}\right] .
$$

When only torsional vibration is considered, according to the Nigol galloping criterion, the third term of the diagonal element in formula (14) is the criterion for judging 
galloping. When the following conditions are met, the system is in a stable state:

$$
\frac{1}{2} \rho d^{2} U \frac{\partial C_{M}}{\partial \alpha}+2 J \omega_{\theta} \zeta_{\theta}>0
$$

In the actual project, the conductor will vibrate in three directions, and the above two galloping criteria cannot meet the current engineering requirements. Due to the coupling of galloping in horizontal, vertical, and torsional directions, galloping becomes more complex, so it is necessary to establish more accurate criteria for determining the galloping of three degrees of freedom. In this paper, the vibration of the iced conductor in three directions is considered simultaneously. In order to analyze the stability of the iced conductor system, let $x=\bar{x} e^{\beta t}$; then the characteristic polynomial can be obtained according to formula (12):

$$
\begin{gathered}
G(\beta)=\operatorname{det}\left(M \beta^{2}+C \beta+K\right)=\sum_{i=0}^{6} a_{i} \beta^{6-i}, \\
\beta^{2} M+\beta C+K=\left[\begin{array}{c}
\beta^{2} m+\frac{1}{2} \beta \rho d U\left(\frac{\partial C_{L}}{\partial \alpha}+C_{D}\right)+2 m \omega_{y} \zeta_{y}+k_{z} \\
\frac{1}{2} \beta \rho d U\left(\frac{\partial C_{D}}{\partial \alpha}-C_{L}\right) \\
\frac{1}{2} \beta \rho d^{2} U \frac{\partial C_{M}}{\partial \alpha}
\end{array}\right.
\end{gathered}
$$

The coefficient of $\beta$ can be obtained by calculating the determinant of the matrix. Let $\mathbf{C}=\left[\begin{array}{lll}c_{11} & c_{12} & c_{13} \\ c_{21} & c_{22} & c_{23} \\ c_{31} & c_{32} & c_{33}\end{array}\right]$; then each coefficient of $\beta$ can be expressed as

$$
\begin{aligned}
a_{0}= & m^{2} J \\
a_{1}= & m^{2} c_{33}+m J c_{22}+m J c_{11}, \\
a_{2}= & m^{2} J\left(\omega_{y}^{2}+\omega_{z}^{2}\right)+m^{3} \omega_{\theta}^{2}+J\left(c_{11} c_{22}-c_{12} c_{21}\right) \\
& +m\left(c_{11} c_{33}+c_{22} c_{33}-c_{13} c_{31}-c_{23} c_{32}\right), \\
a_{3}= & m^{2}\left(\omega_{y}^{2}+\omega_{z}^{2}\right) c_{33}+m \omega_{\theta}^{2}\left(c_{11}+c_{22}\right)+m J\left(\omega_{z}^{2} c_{11}+\omega_{y}^{2} c_{22}\right) \\
& +c_{11} c_{22} c_{33}-c_{11} c_{23} c_{32}+c_{12} c_{23} c_{31}-c_{12} c_{21} c_{33} \\
& +c_{13} c_{21} c_{32}-c_{13} c_{22} c_{31}, \\
a_{4}= & m^{2} J \omega_{y}^{2} \omega_{z}^{2}+m^{3}\left(\omega_{y}^{2} \omega_{\theta}^{2}+\omega_{z}^{2} \omega_{\theta}^{2}\right) \\
& +m\left(\omega_{y}^{2} c_{22} c_{33}+\omega_{z}^{2} c_{11} c_{33}+\omega_{\theta}^{2} c_{11} c_{22}-\omega_{z}^{2} c_{13} c_{31}\right. \\
& \left.-\omega_{y}^{2} c_{23} c_{32}-\omega_{\theta}^{2} c_{21} c_{12}\right), \\
a_{5}= & m^{2} \omega_{y}^{2} \omega_{z}^{2} c_{33}+m^{2} \omega_{y}^{2} \omega_{\theta}^{2} c_{22}+m^{2} \omega_{z}^{2} \omega_{\theta}^{2} c_{11}, \\
a_{6}= & m^{3} \omega_{y}^{2} \omega_{z}^{2} \omega_{\theta}^{2} .
\end{aligned}
$$

If the matrix $\beta^{2} M+\beta C+K$ is a positive definite matrix, then the 3 -DOF dynamic system is stable. Use the Routh-Hurwitz criterion to judge the positive definiteness of the matrix. When the following conditions are met, the system is in a stable state:

$$
\gamma_{i}>0, \quad i=1 \sim 6
$$

$$
\left.\begin{array}{cc}
\beta \rho d U C_{L} & \frac{1}{2} \beta \rho d U\left(\frac{\partial C_{L}}{\partial \alpha}+C_{D}\right) \\
\beta^{2} m+\beta \rho d U C_{D}+2 \beta m \omega_{z} \zeta_{z}+k_{y} & \frac{1}{2} \beta \rho d U\left(\frac{\partial C_{D}}{\partial \alpha}-C_{L}\right) \\
\beta \rho d^{2} U C_{M} & \beta^{2} J+\frac{1}{2} \beta \rho d^{2} U \frac{\partial C_{M}}{\partial \alpha}+2 J \omega_{\theta} \zeta_{\theta}+k_{\theta}
\end{array}\right]
$$

where $\gamma_{i}$ is the main determinant of each order of the Hurwitz coefficient matrix. The Hurwitz coefficient matrix $Q$ can be expressed as

$$
Q=\left[\begin{array}{cccccc}
a_{1} & a_{0} & 0 & 0 & 0 & 0 \\
a_{3} & a_{2} & a_{1} & a_{0} & 0 & 0 \\
a_{5} & a_{4} & a_{3} & a_{2} & a_{1} & a_{0} \\
0 & a_{6} & a_{5} & a_{4} & a_{3} & a_{2} \\
0 & 0 & 0 & a_{6} & a_{5} & a_{4} \\
0 & 0 & 0 & 0 & 0 & a_{6}
\end{array}\right] .
$$

2.3. Galloping Modal Analysis of the Iced Conductor. The modal frequency of the conductor is the basis of studying conductor galloping, and the frequency of the conductor vibration is also needed to calculate the critical wind speed of the conductor. Considering that the frequency of the conductor is related to the physical parameters of the conductor, the frequency characteristics of the single span conductor are discussed below. According to [26], the control equations of in-plane and out-of-plane vibration of single span conductor are as follows:

$$
\begin{aligned}
\frac{\partial}{\partial s}\left[\left(H+h_{\tau}\right) \frac{\partial(y+v)}{\partial z}\right] & =m \frac{\partial^{2} v}{\partial t^{2}}-m g \\
H \frac{\partial^{2} w}{\partial z^{2}} & =m \frac{\partial^{2} w}{\partial t^{2}},
\end{aligned}
$$

where formula (21a) is the vibration control equation in plane of the conductor and formula (22b) is the vibration control equation out of plane of the conductor. $H$ is the 
horizontal tension of the conductor under the self-weight. $h_{\tau}$ is the dynamic tension. $y, z$ are the vertical and horizontal coordinates of the conductor under the self-weight. $v, w$ is the vertical and horizontal displacement of the conductor under the external load. $m$ is the mass of the conductor per unit length. $s$ is the arc coordinate along the length of the conductor, and $t$ is the time. The solution of formula (21a) is complex, which can be divided into symmetrical mode and antisymmetric mode. According to the solution of the equation, the expression of in-plane mode of the conductor can be obtained as follows:

$$
\begin{aligned}
& \psi_{n}=\frac{1}{A}\left[1-\cos \left(\frac{\bar{\omega}_{n} z}{l}\right)-\tan \left(\frac{\bar{\omega}_{n}}{2}\right) \sin \left(\frac{\bar{\omega}_{n} z}{l}\right)\right], \quad n=1,3,5, \ldots \\
& \psi_{n}=\sin \left(\frac{\bar{\omega}_{n} z}{l}\right), \quad n=2,4,6, \ldots,
\end{aligned}
$$

where $A$ is the normalized modal coefficient, $\bar{\omega}$ is the dimensionless frequency, $f$ is the frequency, $l$ is the conductor span, and $n$ is the modal order.

The solution of equation (21b) is relatively simple. According to the solution of the equation, the out-of-plane mode of the conductor can be obtained as follows:

$$
\phi_{n}=\sin \left(\frac{\bar{\omega}_{n} z}{l}\right), \quad n=1,2,3, \ldots
$$

According to formulas (21a) and (22), the dimensionless frequency of in-plane symmetrical mode and antisymmetric mode can be determined as

$$
\begin{aligned}
\tan \left(\frac{\bar{\omega}_{n}}{2}\right) & =\frac{1}{2} \bar{\omega}_{n}\left(1-\frac{\bar{\omega}_{n}^{2}}{\lambda^{2}}\right), \quad n=1,3,5, \ldots, \\
\bar{\omega}_{n} & =n \pi, \quad n=2,4,6, \ldots,
\end{aligned}
$$

where the comprehensive parameter $\lambda$ can be expressed as

$$
\lambda=\frac{m g l}{H} \sqrt{\frac{E A}{H}} .
$$

The comprehensive parameter $\lambda$ is affected by the tensile rigidity $E A$, the initial tension $H$, the mass per unit length $m$, and the span $l$ of the conductor. The comprehensive parameter $\lambda$ reflects the physical characteristics of the conductor comprehensively and is an important parameter to study the vibration of the conductor. According to formulas (21b) and (23), it can be determined that the out-of-plane dimensionless frequency is

$$
\bar{\omega}_{n}=n \pi, \quad n=2,4,6, \ldots
$$

According to the boundary conditions, the relationship between dimensionless frequency $\bar{\omega}_{n}$ and frequency $f$ can be expressed as

$$
\bar{\omega}_{n}=2 f \pi l \sqrt{\frac{m}{H}}
$$

Physical parameters of the iced conductor are given in Table 1 .
Substituting the physical parameters of the iced conductor into formulas (24)-(26), we can get the change characteristics of dimensionless frequency $\bar{\omega}_{n}$ with the comprehensive parameter $\lambda$, as shown in Figure 3 .

It can be seen from the figure that the dimensionless frequency corresponding to the first out-of-plane symmetric mode $\varphi_{1}$ is 1 , and its value does not change with $\lambda$. The dimensionless frequency corresponding to the first in-plane symmetric mode $\psi_{1}$ increases with the increase of $\lambda$, and its value range is $1 \sim 2.86$. The dimensionless frequencies corresponding to the second in-plane antisymmetric mode $\psi_{2}$ and out-of-plane antisymmetric mode $\varphi_{2}$ are the same, their values do not change with $\lambda$, and their values are 2 . The dimensionless frequency corresponding to the third out-ofplane symmetric mode $\varphi_{3}$ is 3 , and its value does not change with $\lambda$. The dimensionless frequency corresponding to the third in-plane symmetric mode $\psi_{3}$ increases with the increase of $\lambda$, and its value range is $3 \sim 4.92$. From formula (24), it can be seen that the comprehensive parameter $\lambda$ is positively related to the mass per unit length of the conductor $m$, the span $l$ of the conductor, and the tensile rigidity $E A$, and the comprehensive parameter $\lambda$ is negatively related to the initial tension $H$. From the overall view, the dimensionless frequencies of the first in-plane symmetric mode $\psi_{1}$ and the third in-plane symmetric mode $\psi_{3}$ decrease with the increase of the initial tension $H$. The initial tension $H$ has a great influence on the dimensionless frequency. According to the observation and analysis of the actual conductor galloping event, it is found that the mode of galloping is mainly low order. Therefore, this paper selects the in-plane mode as $\psi_{1}$ and the out-of-plane mode as $\varphi_{1}$ when the gallop occurs. In order to verify the correctness of the analytical solution of modal frequency, the finite element software ABAQUS is used for numerical simulation. The finite element model of the iced conductor is established in ABAQUS, and the fixed constraints are adopted at both ends of the conductor. Considering that the span of the conductor is far larger than the diameter of the conductor, the influence of bending stiffness is ignored and three-node parabolic truss element is used to simulate the conductor. The conductor model is divided into 200 grids. The equivalent node load of truss element is composed of aerodynamic force and gravity on the conductor. Since galloping of the conductor is a typical nonlinear problem, the stiffness matrix, element unbalance force vector, and nonlinear aerodynamic load vector should be updated; according to the current displacement, after the incremental solution of each load step is completed. In order to reduce the calculation as much as possible and improve the efficiency of galloping analysis, the degree of freedom condensation method is used in this study. After the load is applied, the conductor frequency obtained by numerical simulation is shown in Figure 4.

The dotted curve in Figure 4 represents the frequency corresponding to the first in-plane symmetric mode $\psi_{1}$. Its frequency decreases with the increase of $\lambda$, and its value is between 0.2 and $0.4 \mathrm{~Hz}$. The square point curve represents the frequency corresponding to the first out-of-plane symmetrical mode $\varphi_{1}$. Its frequency increases first and then decreases with the increase of $\lambda$, and its value is between 0.4 
TABle 1: Physical parameters of the iced conductor.

\begin{tabular}{lccc}
\hline Parameters & Notation & Units & $\begin{array}{c}\text { Numerical } \\
\text { value }\end{array}$ \\
\hline Mass per unit length & $\mathrm{m}$ & $\mathrm{kg} /$ & 1.53 \\
Moment of inertia & $J_{\theta}$ & $\mathrm{kg} \mathrm{m}$ & 0.0057 \\
Diameter of bare cable & $d$ & $\mathrm{~m}$ & $27.6 \times 10^{-3}$ \\
Span length & $l$ & $\mathrm{~m}$ & 200 \\
Damping ratio in the $y, z$ direction & $\zeta_{y}, \zeta z$ & & 0.005 \\
Damping ratio in the $\theta$ direction & $\zeta_{\theta}$ & & 0.038 \\
Axial rigidity & $E A$ & $\mathrm{~N}$ & $13.3 \times 10^{6}$ \\
Horizontal tension & $H$ & $\mathrm{~N}$ & $41.65 \times 10^{3}$ \\
\hline
\end{tabular}

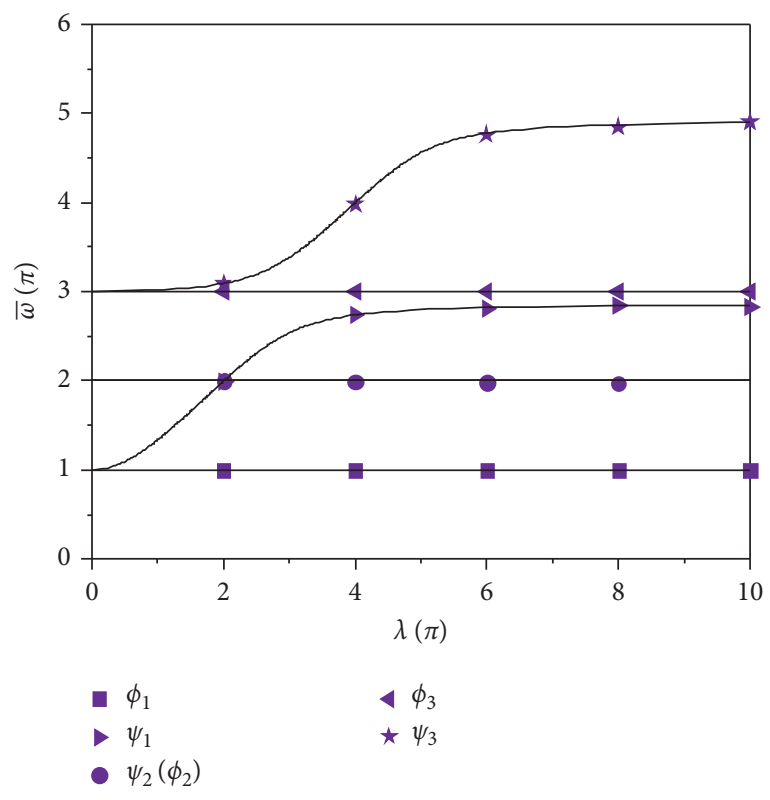

Figure 3: Dimensionless natural frequencies.

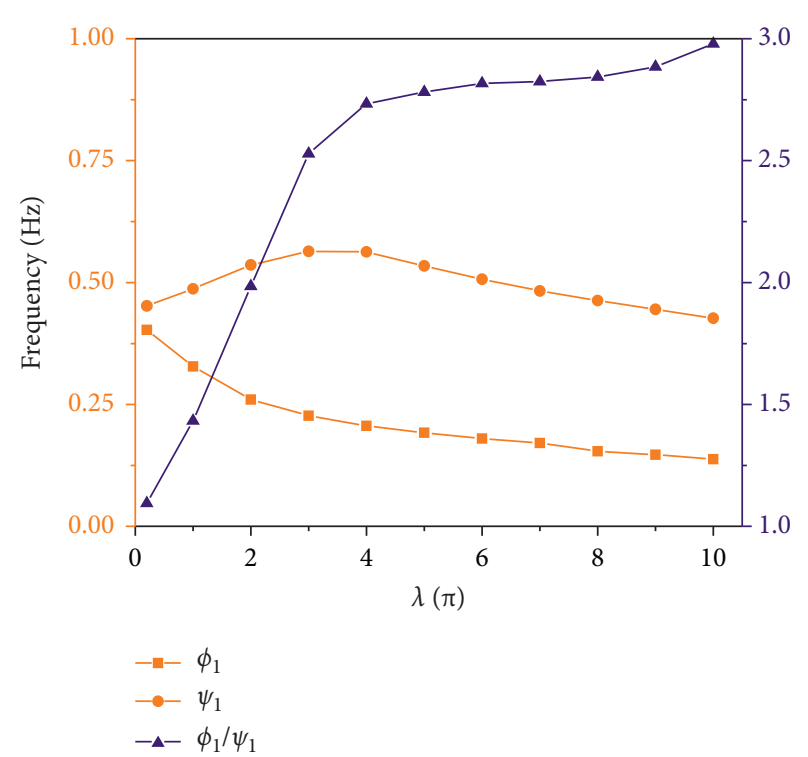

FIGURE 4: Frequency corresponding to first-order in-plane and outof-plane modes. and $0.6 \mathrm{~Hz}$. In the entire interval, the in-plane frequency is greater than the out-of-plane frequency. The triangle point curve represents the ratio of the first in-plane frequency to the out-of-plane frequency. In the interval, the frequency ratio rises, and its value is between 1.12 and 2.99. The first inplane and out-of-plane frequency ratio triangle curve in Figure 4 coincides with the first in-plane and out-of-plane ratio frequency triangle curve in Figure 3, indicating that the analytical solution of frequency coincides with the numerical solution, which proves the correctness and authenticity of the frequency solution.

\section{Wind Tunnel Test and Aerodynamic Characteristics Analysis of the Iced Conductor}

The previous chapter completes the derivation of the calculation formula of the critical wind speed of the iced conductor and the analysis of the conductor mode. The calculation of the critical wind speed requires the aerodynamic coefficient of the iced conductor. The aerodynamic coefficient provides raw data support for the calculation of the critical wind speed. The analysis of aerodynamic characteristics can explain the cause of the conductor galloping.

3.1. Wind Tunnel Equipment. This test was conducted in a $1.4 \mathrm{~m} \times 1.4 \mathrm{~m}$ low-speed wind tunnel at the China Aerodynamics Research and Development Center Low Wind Speed Research Institute. The wind tunnel is shown in Figure 5. The wind tunnel is a direct-flow low wind speed wind tunnel. The cross-sectional area of the test section is $1.8632 \mathrm{~m}^{2}$, the cross-sectional shape is a chamfered rectangle, the length of the test section is $2.8 \mathrm{~m}$, and the test wind speed range is $0 \sim 65 \mathrm{~m} / \mathrm{s}$.

The PXI system is selected as the data collection system for the test of the iced conductor. Angle control, speed, and pressure control are realized by corresponding engineering control system. The instructions are transmitted by network communication between devices.

3.2. Iced Conductor Model. This test simulates a transmission line located in the Da Feng Ding area of Xi Chang City, Sichuan Province, China. The type of transmission line in this area is XLGJ-400/50, the safety of transmission line factor is 2.5 , the maximum operating stress of transmission line is $105.9 \mathrm{MPa}$, and the average operating stress of transmission line is $66.2 \mathrm{MPa}$. The diameter of transmission line is $27.6 \mathrm{~mm}$. The material of the conductor test model is duralumin, with a diameter of $27.6 \mathrm{~mm}$ and a length of $700 \mathrm{~mm}$. The outer surface is coiled with a rubber tube to simulate the outer surface of the actual transmission line. An aerodynamic balance is installed inside the conductor model. The conductor model is shown in Figure 6.

The material of the ice model is light wood with a length of $700 \mathrm{~mm}$. During the test, the ice model is pasted on the surface of the conductor model. The iced cross-sectional shape is symmetrical crescent shape and sector shape. The sector shape outer arc angle is $120^{\circ}$ and the inner arc angle is 


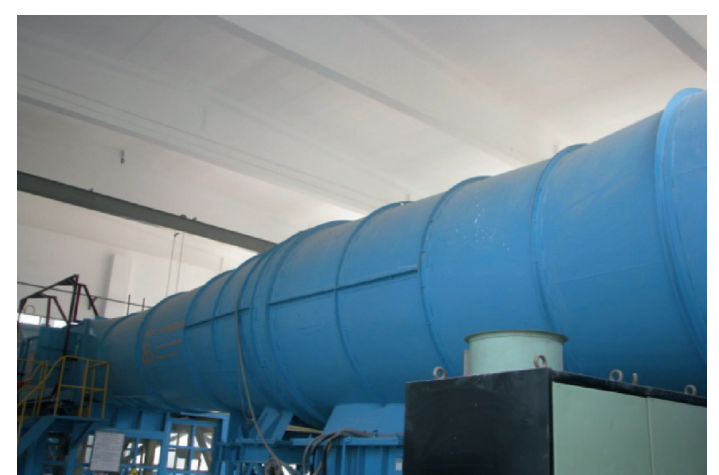

FIgURE 5: Wind tunnel with low wind speed $(1.4 \mathrm{~m} \times 1.4 \mathrm{~m})$.

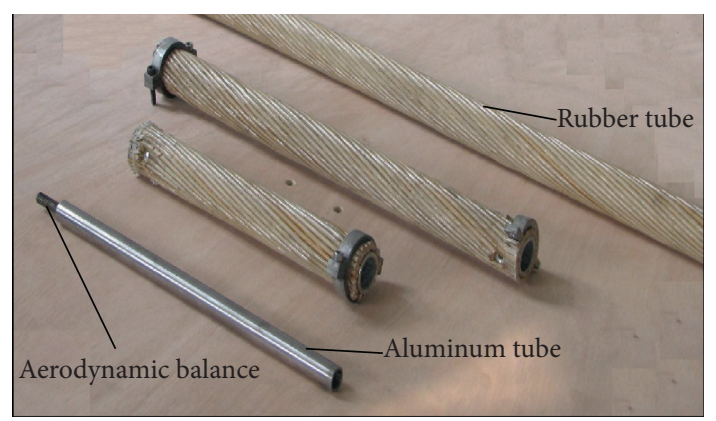

Figure 6: Conductor model.

$140^{\circ}$. The wind angle of attack is defined as the angle between the counterflow direction and the symmetry axis of the iced section, facing the incoming flow direction, and turning counterclockwise is positive. The initial attack angle is $0^{\circ}$. Each time the aerodynamic coefficient is measured, the conductor model rotates $5^{\circ}$, and the rotation angle range is $0^{\circ} \sim 180^{\circ}$. The ice size and attack angle are shown in Figure 7. The influence of torsional vibration on aerodynamic force during galloping is not considered, the use of quasistatic assumptions has little effect on the results. However, the effect of this assumption on the aerodynamic stability of the conductor can be neglected.

The thickness of crescent ice is $12 \mathrm{~mm}, 20 \mathrm{~mm}$, and $28 \mathrm{~mm}$, respectively, and that of sector ice is $18 \mathrm{~mm}$ and $25 \mathrm{~mm}$, respectively. The ice model is shown in Figure 8.

3.3. Test Device of the Conductor. In the middle of the iced conductor test device is a conductor model. To ensure the two-dimensional characteristics of the fluid, circular end plates are installed at both ends of the conductor model as shown in Figure 9. A gap of about $5 \mathrm{~mm}$ is left between the lower end of the conductor model and the lower end plate to ensure no contact between the model and the lower end plate during the test. The supporting rod of the aerodynamic balance directly passes through the upper end plate and is fixedly connected with the fixed rack of the supporting device. During the test, the attack angle is changed by turning upper and lower turntable synchronously.
3.4. Test Content and Data Processing. The content of this test is to test the aerodynamic coefficient of the iced conductor model under different attack angles, different wind speeds, different ice shapes, and different ice thickness. The aerodynamic coefficients include drag coefficient, lift coefficient, and torque coefficient. The dimensionless aerodynamic coefficient is defined as follows:

$$
\begin{gathered}
C_{L}=\frac{2 F_{L}}{\rho U^{2} L d}, \\
C_{D}=\frac{2 F_{D}}{\rho U^{2} L d}, \\
C_{M}=\frac{2 M}{\rho U^{2} L d^{2}},
\end{gathered}
$$

where $d$ is the diameter of the conductor model, $d=26.7 \mathrm{~mm}, U$ is the test wind speed, $L$ is the length of the conductor, $L=700 \mathrm{~mm}, \rho$ is the air density under the test environment, and $\rho=1.29 \mathrm{~kg} / \mathrm{m}^{3}$. The coordinate system is the wind axis coordinate system. Due to the small windward area perpendicular to the airflow, the wind tunnel blockage is very small, and the data will not need to be corrected.

\subsection{Test Results and Aerodynamic Characteristics Analysis}

3.5.1. Influence of Wind Speed on the Aerodynamic Coefficient. Test the aerodynamic coefficients of the crescent iced conductor with an ice thickness of $12 \mathrm{~mm}$ at four wind speeds of $10,12,14$, and $18 \mathrm{~m} / \mathrm{s}$. The test results are shown in Figure 10.

It can be seen from Figure 10 that, under different wind speeds, the curve of aerodynamic coefficient changing with the angle of attack is approximately the same, and the wind speed has little influence on the aerodynamic coefficient of the iced conductor. It can be seen from Figure 10(a) that the curve of the lift coefficient with the angle of attack is approximately sinusoidal. When the angle of attack $\alpha=0^{\circ}$, $\alpha=90^{\circ}$, and $\alpha=180^{\circ}$, the lift coefficient is almost zero. At the same angle of attack, with the increase of wind speed, the change of lift coefficient is very small, and the change is not regular. It can be seen from Figure 10(b) that the curve of the drag coefficient of the conductor with the angle of attack is a half-wave shape. When the angle of attack $\alpha=0^{\circ}$, the windward area of the conductor is the smallest and the drag coefficient is the smallest. When the angle of attack $\alpha=90^{\circ}$, the windward side of the conductor is the largest, and the drag coefficient has a peak value. At the same angle of attack, with the increase of wind speed, the drag coefficient decreases, but the change value is very small. It can be seen from Figure 10(c) that the curve of the conductor torque coefficient changing with the angle of attack is approximately sinusoidal. When the angle of attack $\alpha=0^{\circ}, \alpha=150^{\circ}$, and $\alpha=180^{\circ}$, the torque coefficient is almost 0 . At the same angle of attack, with the increase of wind speed, the torque coefficient is almost unchanged. 


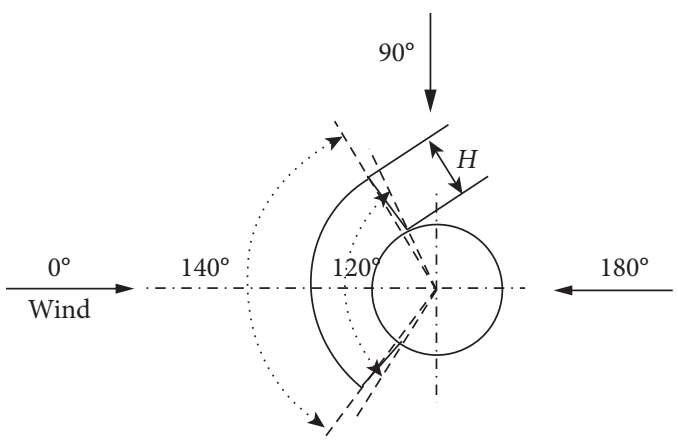

(a)

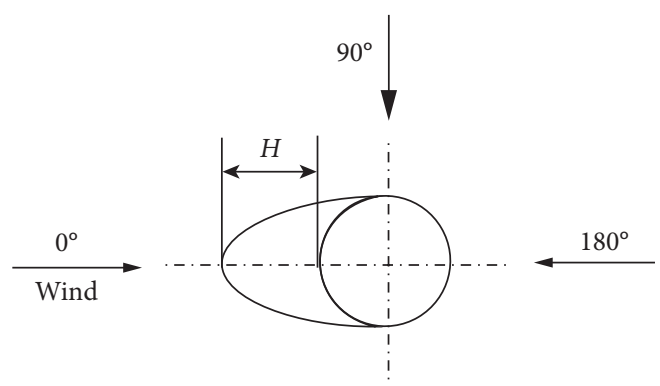

(b)

Figure 7: Iced size and attack angle. (a) Sector. (b) Crescent.

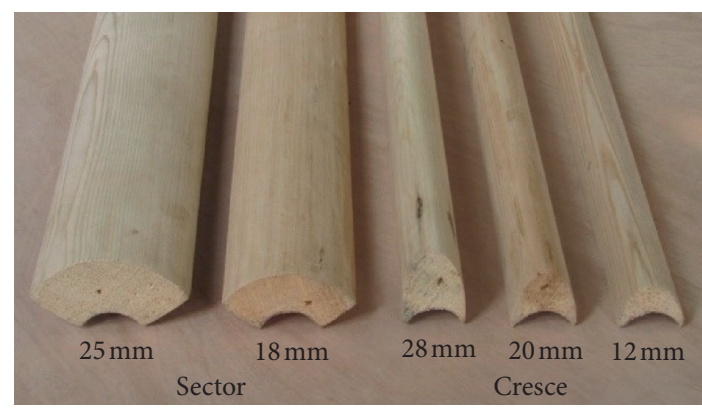

Figure 8: Iced model.

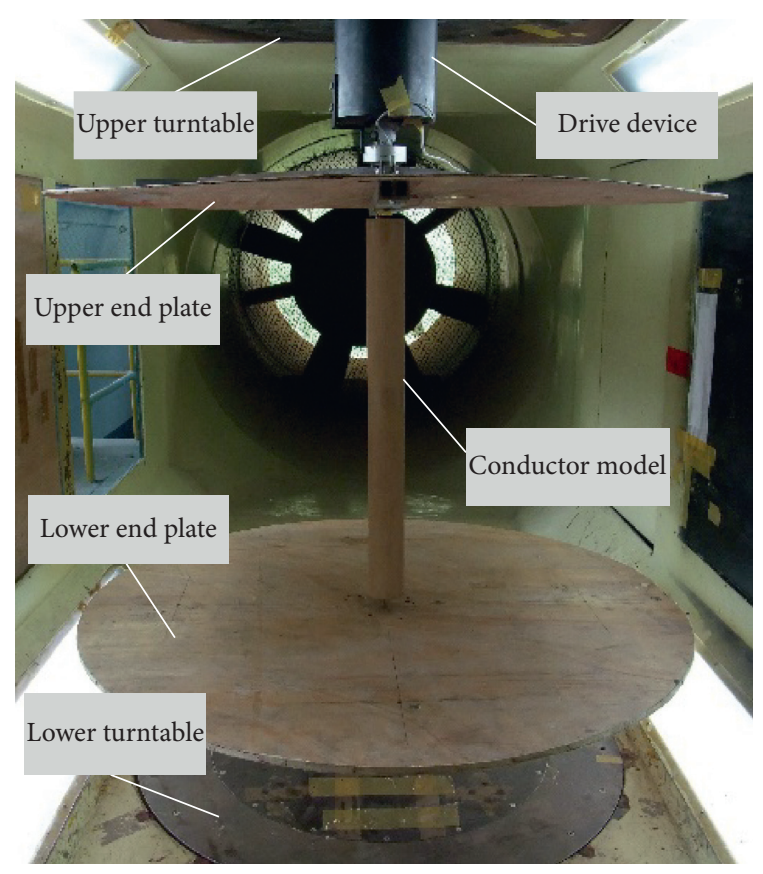

Figure 9: Test device of the conductor.

3.5.2. Influence of Ice Thickness on the Aerodynamic Coefficient. At a wind speed of $14 \mathrm{~m} / \mathrm{s}$, the aerodynamic coefficients of the crescent iced conductor at three thicknesses of 12,20 , and $28 \mathrm{~mm}$ were tested. The test results are shown in Figure 11.
It can be seen from Figure 11 that under different icing thickness, the curve of aerodynamic coefficient changing with the angle of attack is approximately the same, but the difference of aerodynamic coefficient is very large, and the icing thickness has a great influence on the aerodynamic coefficient of the conductor. At the same angle of attack, with the increase of ice thickness, the absolute value of aerodynamic coefficient increases.

3.5.3. Influence of Ice Shape on Aerodynamic Coefficient. When the wind speed is $14 \mathrm{~m} / \mathrm{s}$, test the aerodynamic coefficient of the iced conductor under the two ice shapes of crescent and sector. In order to make the cross-sectional area of the two ice conductors approximately the same, the ice thickness is $20 \mathrm{~mm}$ for crescent and $18 \mathrm{~mm}$ for sector. The test results are shown in Figure 12.

It can be seen from Figure 12 that, for different ice shapes, the curves of aerodynamic coefficients changing with angle of attack are different, and the ice shape has a great influence on the aerodynamic coefficients of the conductor. Different ice shapes will lead to different windward areas of the conductor, which will lead to different aerodynamic coefficients. At the same attack angle, the ice shape is different, the aerodynamic coefficients are very different, and the sign may also be different. Sometimes, the aerodynamic coefficients of the crescent ice conductor are larger than those of the sector ice conductor; sometimes, the aerodynamic coefficients of the sector ice conductor are larger than those of the crescent ice conductor; there is no uniform law. For the lift coefficient, the maximum value of the lift coefficient of the crescent ice conductor exactly corresponds to the minimum value of the lift coefficient of the sector ice conductor. For the torque coefficient, the curve of the torque coefficient of the crescent iced conductor and the curve of the torque coefficient of the sector iced conductor have the same trend changing with the attack angle.

\section{Calculation and Analysis of Critical Wind Speed}

Use MATLAB to write judgment and loop statement programs and substitute the aerodynamic coefficients obtained in chapter 3 and the conductor frequency 


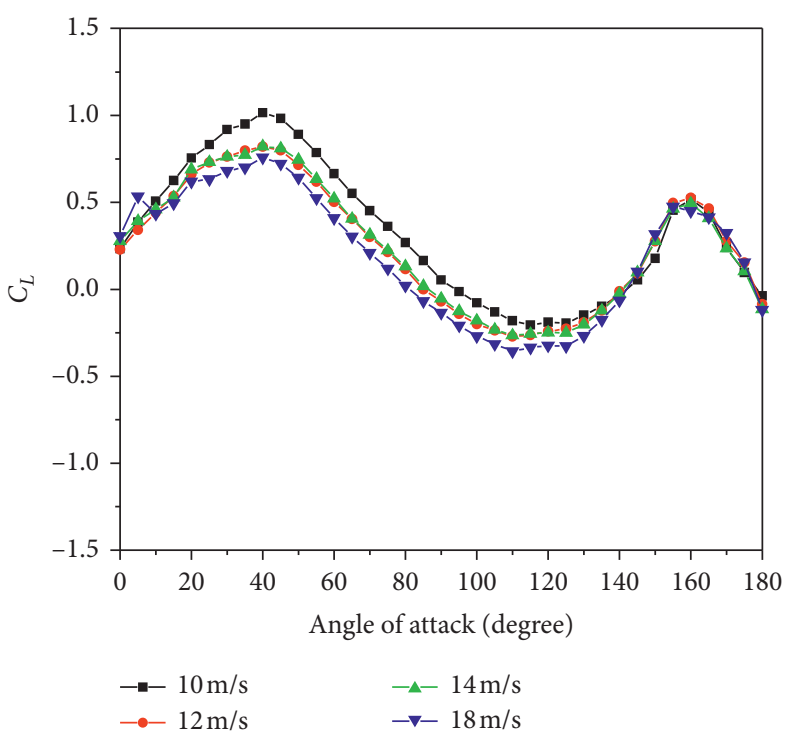

(a)

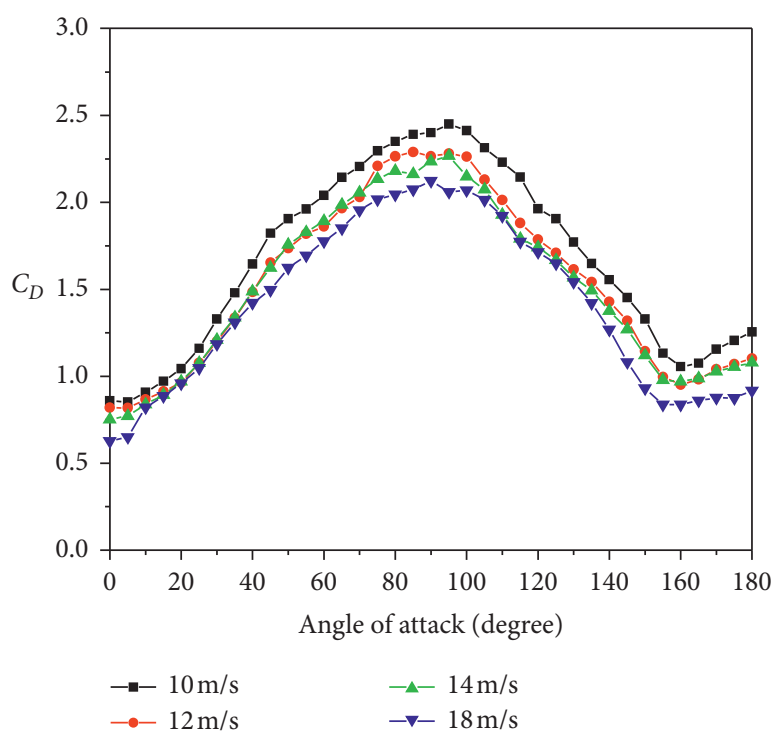

(b)

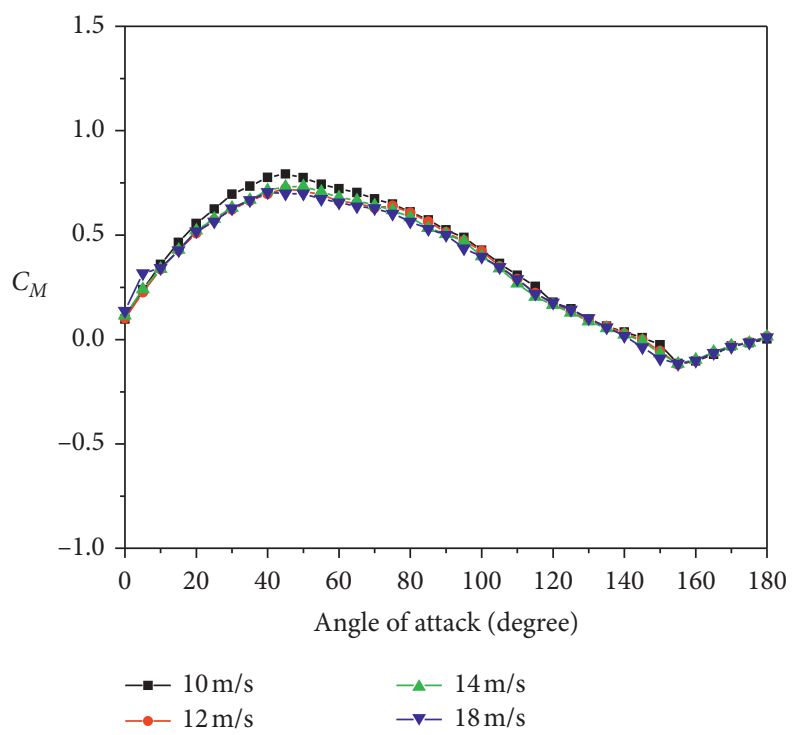

(c)

Figure 10: Aerodynamic coefficient of the iced conductor at different wind speeds. (a) Lift coefficient. (b) Drag coefficient. (c) Torque coefficient.

obtained in chapter 2 into the stability discriminant formulas (15), (16), and (19) to calculate different galloping judgment criteria under various engineering situations critical wind speed. This chapter compares and analyzes the critical wind speeds calculated by different galloping criteria. Set different variables and analyze the influence of the comprehensive conductor parameter, torsion frequency, ice thickness, and ice shape on the critical wind speed. Regarding the torsion frequency of the iced conductor, there is no generally accepted research result. In order to make the result reasonably representative, this paper selects three torsion frequency values for calculation, namely, $0.2 \mathrm{~Hz}, 0.4 \mathrm{~Hz}$, and $0.6 \mathrm{~Hz}$. The results of the calculation are now analyzed:
4.1. Comparative Analysis of Critical Wind Speeds with Den Hartog and Nigol. According to the calculation results, the critical wind speeds of three different galloping theories at a crescent iced coating thickness of $20 \mathrm{~mm}$, a torsional frequency of $0.4 \mathrm{~Hz}$, and an attack angle of $165^{\circ}$ are selected to compare and verify the $3-\mathrm{DOF}$ galloping discrimination proposed in this paper. The result is shown in Figure 13.

The black curve represents the critical wind speed determined by Den Hartog theory, the red curve represents the critical wind speed determined by Nigol theory, and the green curve represents the critical wind speed determined by the 3-DOF theory in this paper. It can be seen from Figure 13 that critical wind speed determined by Den Hartog theory increases first and then decreases as the frequency ratio 


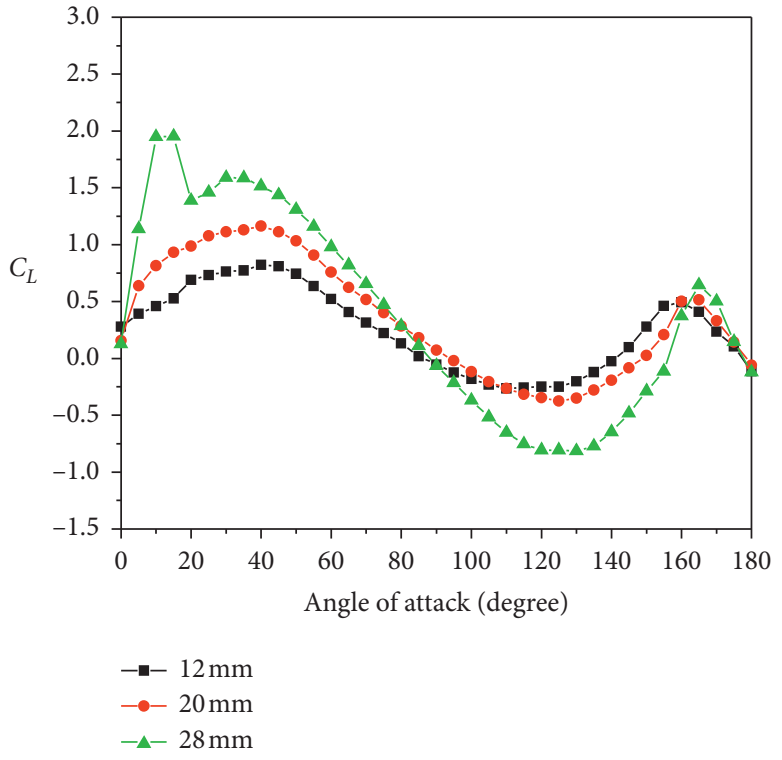

(a)

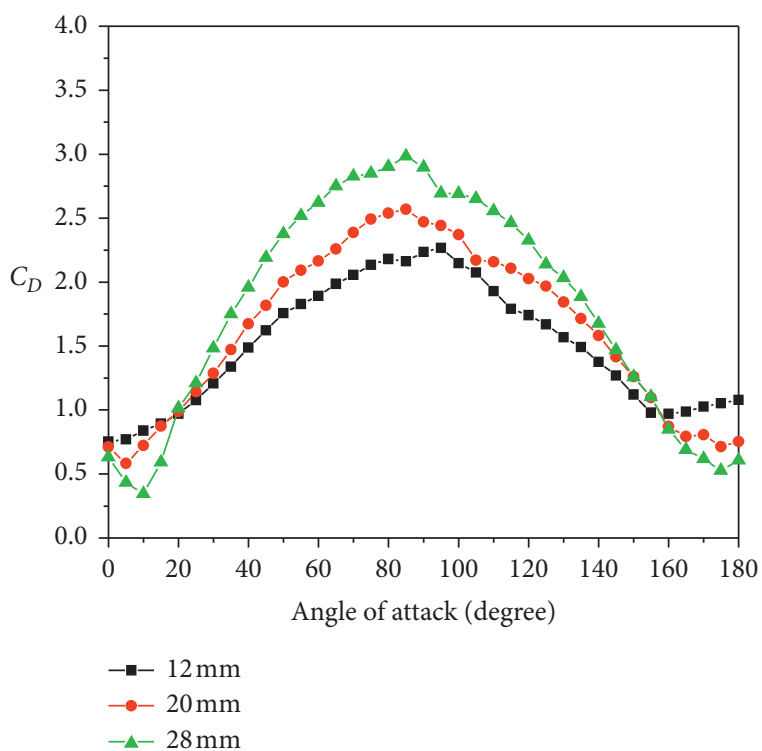

(b)

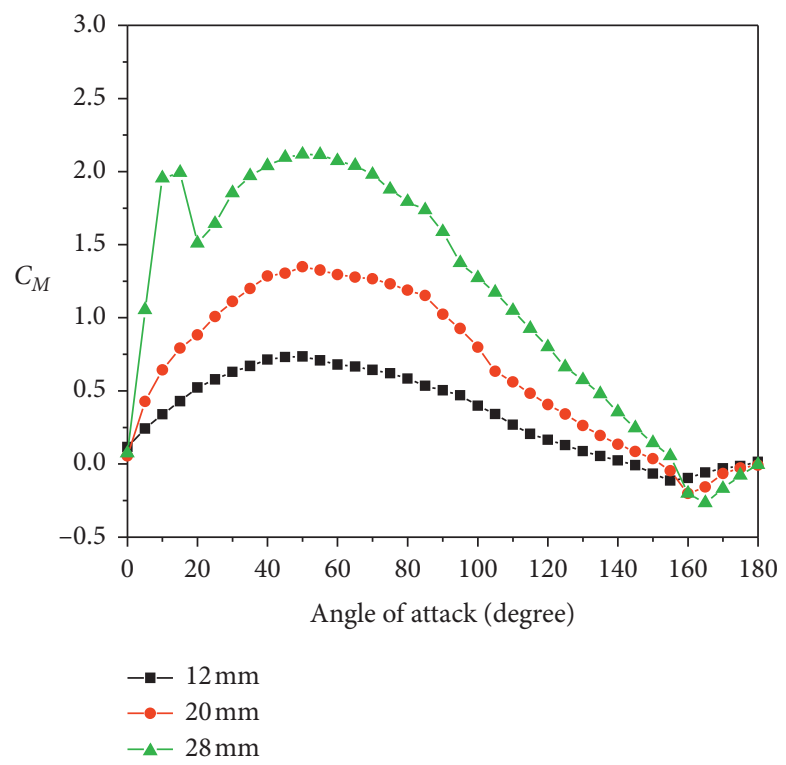

(c)

Figure 11: Aerodynamic coefficient of the iced conductor at different ice thicknesses. (a) Lift coefficient. (b) Drag coefficient. (c) Torque coefficient.

increases, and its value is between 6 and $7.5 \mathrm{~m} / \mathrm{s}$. Critical wind speed determined by Nigol theory does not change with the frequency ratio, and its value is $6.2 \mathrm{~m} / \mathrm{s}$. It can be seen from formula (16) that Nigol theory has nothing to do with in-plane and out-of-plane frequencies, so its critical wind speed will not change with the ratio of in-plane and out-of-plane frequencies and is a fixed value. Critical wind speed determined by the 3-DOF theory in this paper increases first and then decreases as the frequency ratio increases, and its value is between 4.6 and $6.2 \mathrm{~m} / \mathrm{s}$. Overall, the critical wind speed determined by Den Hartog theory is the largest, and the critical wind speed determined by the 3-DOF theory in this paper is the smallest. When the frequency ratio is 1.8 , the critical wind speed is the largest. Since the 3-DOF theory in this paper is related to frequencies in three directions, considering the transfer of energy between three degrees of freedom, the critical wind speed is lower, and galloping is more likely to occur.

4.2. Effect of Torsion Frequency on Critical Wind Speed. In order to analyze the influence of torsion frequency on the critical wind speed of the iced conductor, according to the calculation results, the crescent-shaped ice coating thickness is $20 \mathrm{~mm}$, the torsion frequency is $0.2 \mathrm{~Hz}, 0.4 \mathrm{~Hz}$, and $0.6 \mathrm{~Hz}$, and the angle of attack is $105^{\circ}$. The 3 -DOF stability 


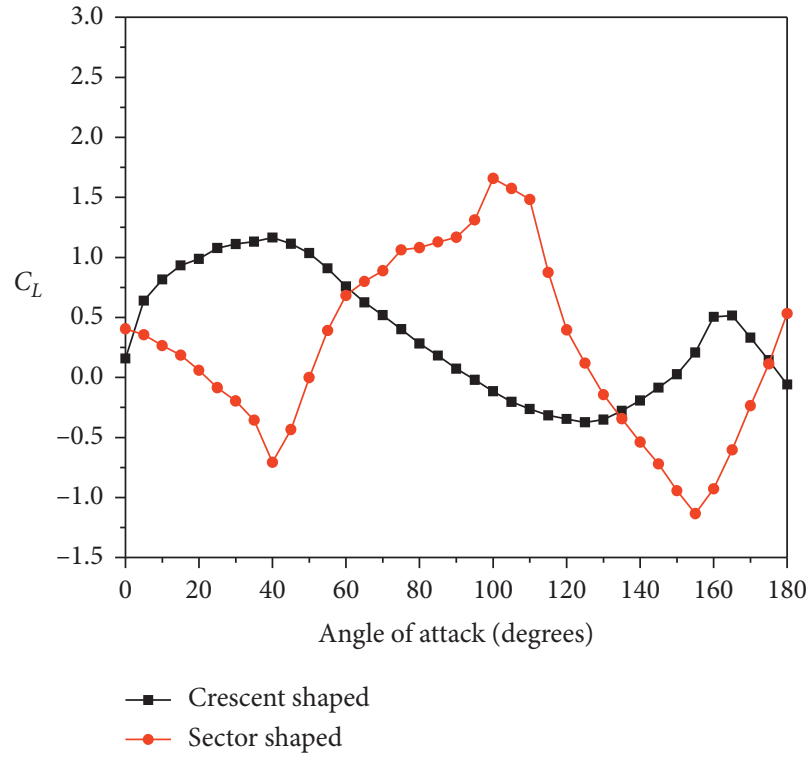

(a)

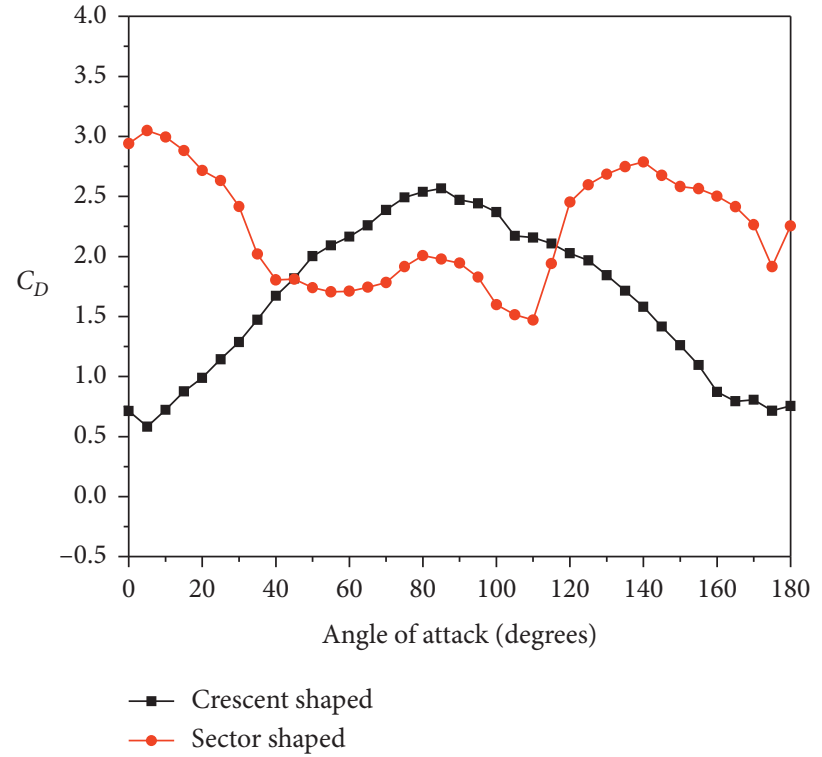

(b)

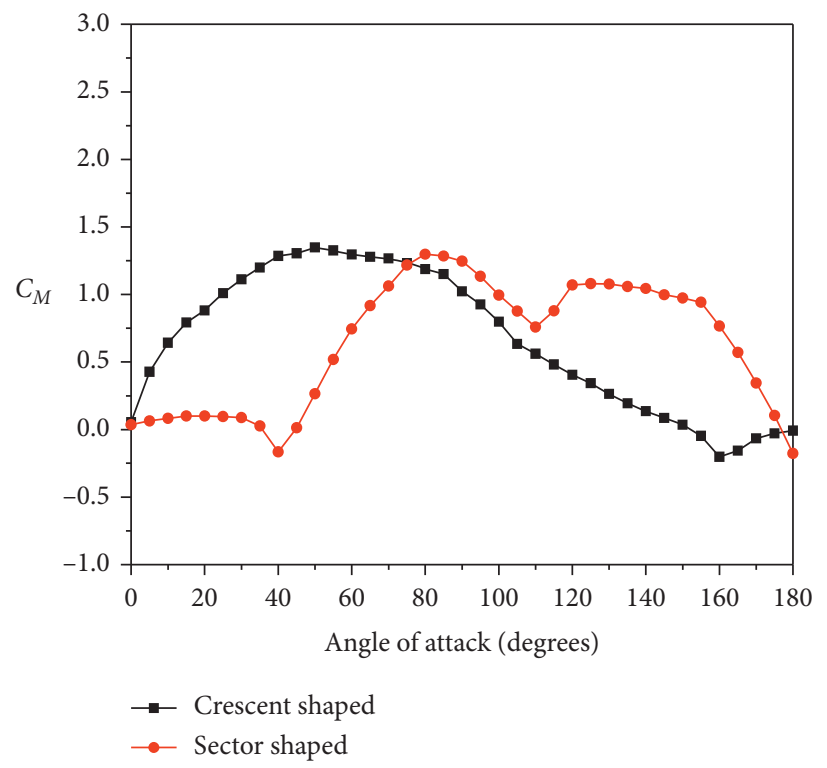

(c)

Figure 12: Aerodynamic coefficient of the iced conductor at different ice shapes. (a) Lift coefficient. (b) Drag coefficient. (c) Torque coefficient.

discriminant formula in this paper gives the critical wind speed as shown in Figure 14.

It can be seen from Figure 14 that the torsional frequency has a greater influence on the critical wind speed. When the torsional frequency is $0.2 \mathrm{~Hz}$ and the torsional frequency is $0.6 \mathrm{~Hz}$, the maximum difference in critical wind speed is $2.4 \mathrm{~m} / \mathrm{s}$. From the analysis of the three curves, as the torsional frequency decreases, the critical wind speed decreases. When the torsional frequency decreases, the torsional stiffness will also decrease, and conductor galloping is more likely to occur. As a whole, the critical wind speed increases first and then decrease as the frequency ratio increases. When the frequency ratio is 1.8 , the critical wind speed reaches its peak value. When the frequency ratio is close to 1 and 3 , the critical wind speed is low, and the conductor is easy to gallop.

4.3. Effect of Ice Thickness on Critical Wind Speed. In order to analyze the influence of ice thickness on the critical wind speed, according to the calculation results, when the torsional frequency is $0.4 \mathrm{~Hz}$ and the attack angle is $90^{\circ}$, the icing shape of the conductor is crescent, under different ice thicknesses. The critical wind speed determined by the theory of 3-DOF in this paper is used. The results are shown in Figure 15. 


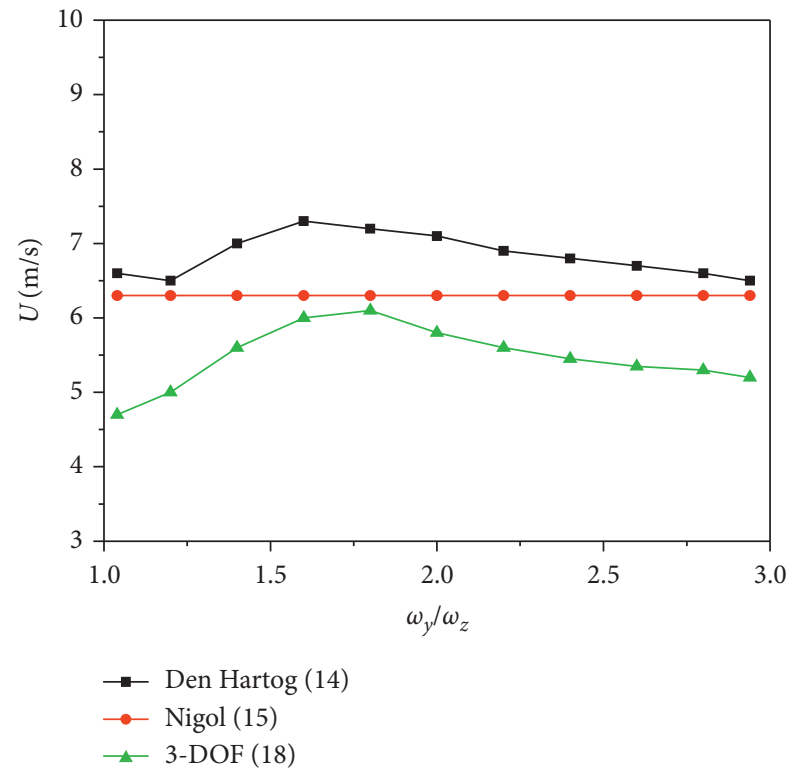

Figure 13: Critical wind speeds at different theories.

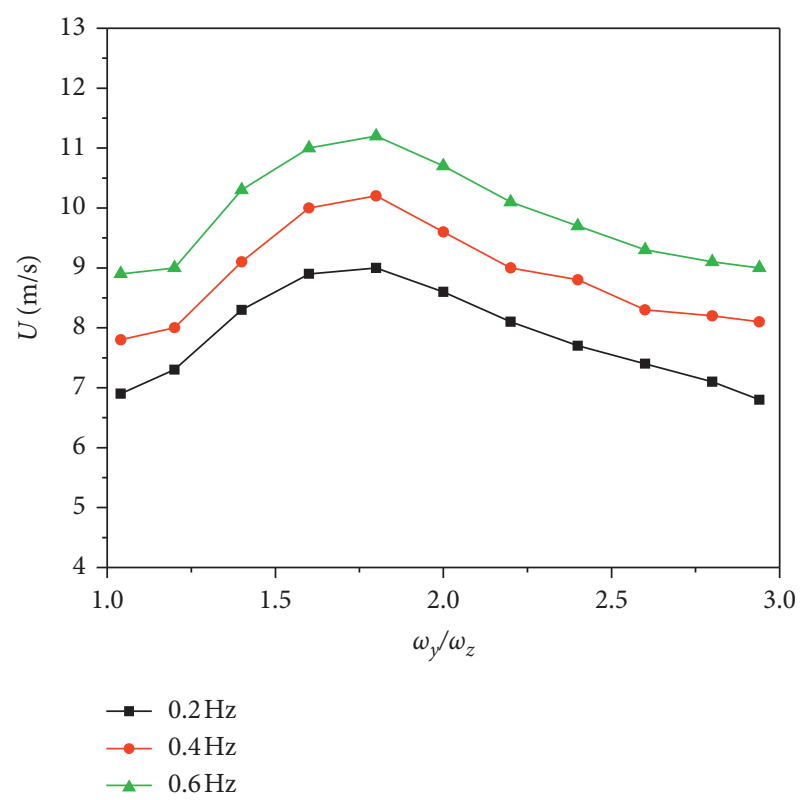

FIGURE 14: Critical wind speeds at different torsion frequencies.

It can be seen from Figure 15 that the thickness of ice has a greater influence on the critical wind speed. When the thickness of ice is $12 \mathrm{~mm}$ and $20 \mathrm{~mm}$, the maximum critical wind speed difference reaches $4 \mathrm{~m} / \mathrm{s}$. As the thickness of the ice increases, the critical wind speed decreases. As the thickness of the ice increases, the windward surface of the conductor increases, and the aerodynamic coefficients in all three directions increase, making the conductor more prone to galloping.

4.4. Effect of Ice Shape on Critical Wind Speed. When analyzing the influence of ice shape on critical wind speed, in order to make the cross-sectional area of two types of the

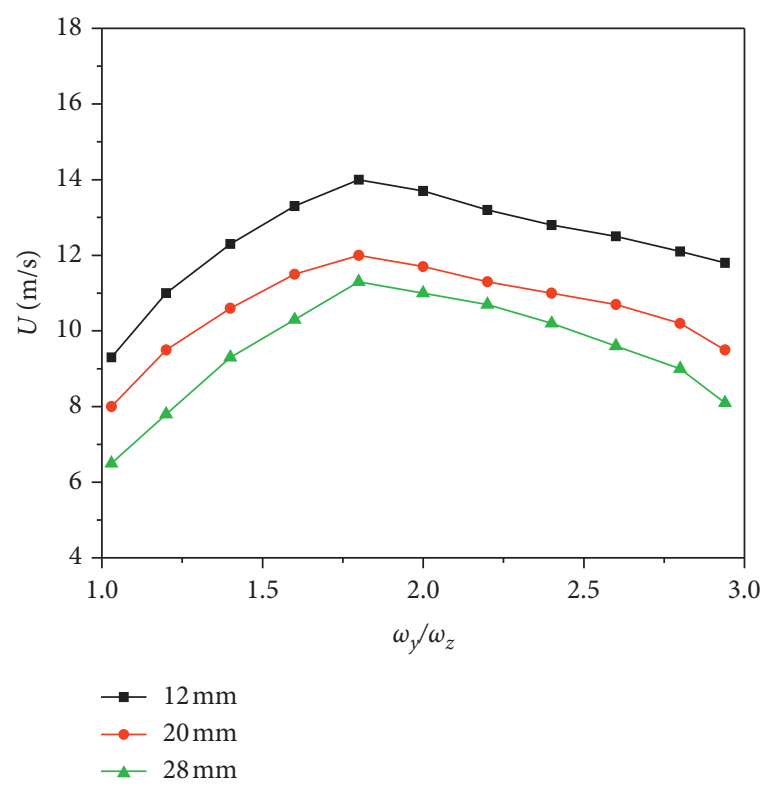

FIGURE 15: Critical wind speeds at different ice thicknesses.

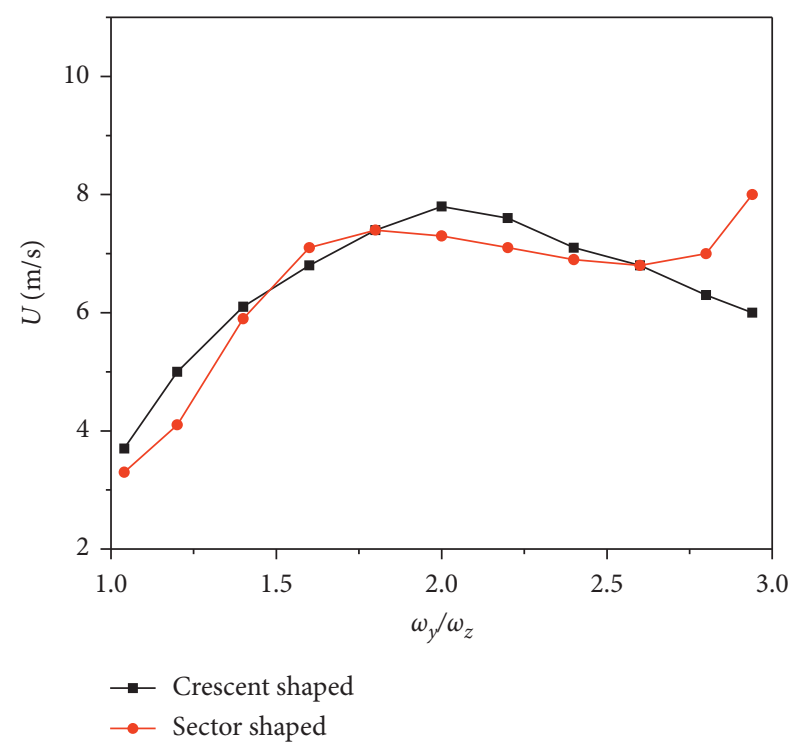

FIgURE 16: Critical wind speeds at different ice shapes.

iced conductors approximately the same, the crescent iced conductor with $20 \mathrm{~mm}$ ice thickness and the sector iced conductor with $18 \mathrm{~mm}$ ice thickness are selected for comparative analysis, excluding the influence of cross-sectional area on critical wind speed. According to the calculation results, the critical wind speed is determined by the 3-DOF theory in this paper when the torsional frequency is $0.4 \mathrm{~Hz}$ and the attack angle is $85^{\circ}$. The results are shown in Figure 16.

As can be seen from Figure 16, the critical wind speeds of the two types of the iced conductor have different trends with the ratio of in-plane and out-plane frequency. As the frequency ratio increases, the critical wind speed of the sector iced conductor increases first, then tends to remain unchanged, and finally increases. As the 
frequency ratio increases, the critical wind speed of the crescent iced conductor increases first and then decreases. In the entire frequency range, sometimes, the critical wind speed of the crescent ice conductor is greater than the critical wind speed of the sector iced conductor, and, sometimes, the critical wind speed of the crescent iced conductor is less than the critical wind speed of the sector iced conductor. There is no uniform rule for the effect of ice shape on the critical wind speed of the conductor galloping, and different conclusions will be drawn for different situations.

\section{Conclusion}

In this paper, the new mechanical model of the 3-DOF iced conductor is established, and the aerodynamic coefficient is expanded by Taylor at the initial angle of attack. The galloping vibration of the iced conductor under static wind is studied, and the vibration equation of the 3-DOF iced conductor is obtained by neglecting the inertia coupling term and the load stiffness term. According to the Routh-Hurwitz stability criterion, the equilibrium stability conditions of the transmission line system are derived. The equation of in-plane and out-of-plane vibration is established, and the influence of physical parameters of the conductor on modal frequency is studied. In the wind tunnel test, different wind speeds, ice thicknesses, and ice shapes are set. The aerodynamic coefficients in three directions of the iced conductor are measured by wind tunnel test. Using Den Hartog theory, Nigol theory, and 3DOF theory, the critical wind speed is calculated and compared. The critical wind speeds of different torsional frequencies, ice thicknesses, and ice shapes are calculated by using the 3-DOF stability discriminant. The characteristics of the critical wind speed with the frequency ratio in and out of plane were investigated. The following conclusions were obtained:

(1) The in-plane and out-of-plane frequencies corresponding to the first-order mode of the conductor obtained by the analytical method and the numerical simulation method are similar, which verifies the accuracy of the results. For the iced single conductor, in the case of other physical parameters of transmission line being the same, the change in conductor tension will significantly affect the in-plane and outof-plane vibration frequencies, and the frequency change will affect the critical wind speed.

(2) The 3-DOF galloping judgment criterion obtained by the method in this paper considers the coupling of vertical motion, lateral motion, and torsional motion in more detail, which is more in accordance with the actual engineering situation. According to the calculation results, based on Den Hartog theory, the attack angles that may occur galloping are $15^{\circ}, 165^{\circ}$, and $170^{\circ}$. Based on Nigol theory, the attack angles that may cause galloping are $10^{\circ}, 165^{\circ}$, $170^{\circ}$. Based on the 3 -DOF stability theory in this paper, the attack angles that may occur galloping are $10^{\circ}, 55^{\circ}, 60^{\circ}, 70^{\circ}, 80^{\circ}, 95^{\circ}, 165^{\circ}$, and $170^{\circ}$; the range of initial angle of attack where galloping occurs is wider than that determined by Den Hartog theory and Nigol theory. The critical wind speed determined by the theory of this paper is lower than the critical wind speed determined by the other two theories. Therefore, it is safer and more reliable to use 3-DOF stability theory in this paper to guide the antigalloping of the transmission line.

(3) The frequency ratio of in-plane and out-of-plane has a significant effect on the critical wind speed of galloping. With the increase of frequency ratio, the critical wind speed first increases and then decreases. When the frequency ratio is close to 1 and 3 , the critical wind speed is low, and the transmission line is prone to galloping. When the frequency ratio is close to 1.8 , the critical wind speed is higher, and the transmission line is not easy to gallop. In the design of transmission line antigalloping, the frequency ratio should be close to 1.8 .

(4) The torsional frequency has a significant effect on the critical wind speed of galloping of iced transmission line. With the decrease of torsional frequency, the critical wind speed decreases; with the decrease of torsional frequency, the torsional stiffness decreases, and the galloping of the conductor is more likely to happen. Therefore, the transmission line parameters with higher torsional frequency should be selected for antigalloping design.

(5) With the increase of ice thickness, the critical wind speed decreases. Under the snowy weather in winter, where the transmission line is easy to be covered with ice, special attention should be paid to the effect of ice on galloping in the design of transmission line antigalloping.

(6) For transmission line with different ice coating shapes, the angle of attack affects the critical wind speed of the transmission line.

\section{Data Availability}

The data used to support the findings of this study are available from the corresponding author upon request.

\section{Conflicts of Interest}

The authors declare no conflicts of interests.

\section{Acknowledgments}

This study was financially supported by the National Inherent Science Foundation of China and Science (Grants nos. 51308570 and 51808085); Technology Research Project of Chongqing Education Commission (Grant no. KJ201600712182); and Basics and Cutting Edge Project of Chongqing Science and Technology Commission (Grant no. cstc2017jcyjAX0246). 


\section{References}

[1] F. Wang, K. Du, J. Sun, F. Huang, and Z. Xiong, "Shaking table array tests of an ultra-high-voltage cup-type transmission tower-line system," Shock and Vibration, vol. 2019, Article ID 2350675, 20 pages, 2019.

[2] T. Ishihara and S. Oka, "A numerical study of the aerodynamic characteristics of ice-accreted transmission lines," Journal of Wind Engineering and Industrial Aerodynamics, vol. 177, pp. 60-68, 2018.

[3] C. B. Gurung, H. Yamaguchi, T. Yukino et al., "Identification of large amplitude wind-induced vibration of ice-accreted transmission lines based on field observed data," Engineering Structures, vol. 24, no. 2, pp. 179-188, 2002.

[4] J. P. D. Hartog, "Transmission line vibration due to sleet," Transactions of the American Institute of Electrical Engineers, vol. 51, no. 4, pp. 1074-1076, 1932.

[5] G. V. Parkinson and N. P. H. Brooks, "On the aeroelastic instability of bluff cylinders," Journal of Applied Mechanics, vol. 28, no. 2, pp. 252-258, 1961.

[6] M. Novak and A. G. Davenport, "Aeroelastic instability of prisms in turbulent flow," Journal of the Engineering Mechanics Division, vol. 96, no. 1, pp. 17-39, 1970.

[7] W. D. Iwan, "Galloping oscillations of hysteretic structures," Journal of the Engineering Mechanics Division, vol. 99, no. 6, pp. 1129-1146, 1973.

[8] O. Nigol and P. Buchan, "Conductor galloping part I-Den Hartog mechanism," IEEE Transactions on Power Apparatus and Systems, vol. PAS-100, no. 2, pp. 699-707, 1981.

[9] O. Nigol and P. Buchan, "Conductor galloping-part II torsional mechanism," IEEE Transactions on Power Apparatus and Systems, vol. PAS-100, no. 2, pp. 708-720, 1981.

[10] P. Yu, A. H. Shah, and N. Popplewell, "Inertially coupled galloping of iced conductors," Journal of Applied Mechanics, vol. 59, no. 1, pp. 140-145, 1992.

[11] X. Liu, L. Liu, M. Cai, and B. Yan, "Free vibration of transmission lines with multiple insulator strings using refined models," Applied Mathematical Modelling, vol. 67, pp. 252-282, 2019.

[12] G. McClure and M. Lapointe, "Modeling the structural dynamic response of overhead transmission lines," Computers \& Structures, vol. 81, no. 8-11, pp. 825-834, 2003.

[13] Y. Liu, Z. Fu, X. H. Yang et al., "Galloping amplitude analysis and observation on full-scale test overhead transmission lines," in Proceedings of the 2015 IEEE Power and Energy Society General Meeting, pp. 1-5, Denver, CO, USA, July 2015.

[14] J. H. G. Macdonald and G. L. Larose, "Two-degree-of-freedom inclined cable galloping-part 1: general formulation and solution for perfectly tuned system," Journal of Wind Engineering and Industrial Aerodynamics, vol. 96, no. 3, pp. 291-307, 2008.

[15] J. Hu, B. Yan, S. Zhou, and H. Zhang, "Numerical investigation on galloping of iced quad bundle conductors," IEEE Transactions on Power Delivery, vol. 27, no. 2, pp. 784-792, 2012.

[16] M. Cai, B. Yan, X. Lu, and L. Zhou, "Numerical simulation of aerodynamic coefficients of iced-quad bundle conductors," IEEE Transactions on Power Delivery, vol. 30, no. 4, pp. 1669-1676, 2015.

[17] A. Luongo, D. Zulli, G. Piccardo et al., "On the effect of twist angle on nonlinear galloping of suspended cables," Computers \& Structures, vol. 87, no. 15-16, pp. 1003-1014, 2009.

[18] A. Luongo, D. Zulli, G. Piccardo et al., "Analytical and numerical approaches to nonlinear galloping of internally resonant suspended cables," Journal of Sound and Vibration, vol. 315, no. 3, pp. 375-393, 2008.

[19] C. B. Gurung, H. Yamaguchi, T. Yukino et al., "Identification and characterization of galloping of Tsuruga test line based on multi-channel modal analysis of field data," Journal of Wind Engineering and Industrial Aerodynamics, vol. 91, no. 7, pp. 903-924, 2003.

[20] N. Barbieri, O. H. de Souza Júnior, R. Barbieri et al., "Dynamical analysis of transmission line cables: part 2-damping estimation," Mechanical Systems and Signal Processing, vol. 18, no. 3, pp. 671-681, 2004.

[21] M. S. Triantafyllou, "The dynamics of taut inclined cables," The Quarterly Journal of Mechanics and Applied Mathematics, vol. 37, no. 3, pp. 421-440, 1984.

[22] M. S. Triantafyllou and L. Grinfogel, "Natural frequencies and modes of inclined cables," Journal of Structural Engineering, vol. 112, no. 1, pp. 139-148, 1986.

[23] Q. Wu, K. Takahashi, and S. Nakamura, "Formulae for frequencies and modes of in-plane vibrations of small-sag inclined cables," Journal of Sound and Vibration, vol. 279, no. 3-5, pp. 1155-1169, 2005.

[24] M. Zhang, G. Zhao, J. Li et al., "Nonlinear dynamic analysis of high-voltage overhead transmission lines," Shock and Vibration, vol. 2018, Article ID 1247523, 35 pages, 2018.

[25] Y. M. Desai, P. Yu, N. Popplewell, and A. H. Shah, "Finite element modelling of transmission line galloping," Computers \& Structures, vol. 57, no. 3, pp. 407-420, 1995.

[26] G. Rega and R. Alaggio, "Experimental unfolding of the nonlinear dynamics of a cable-mass suspended system around a divergence-Hopf bifurcation," Journal of Sound and Vibration, vol. 322, no. 3, pp. 581-611, 2009. 